\title{
LEGAL DIMENSION OF TRADITIONAL AND COMPLEMENTARY MEDICINE PRACTICES IN TURKEY
}

\author{
Zeynep Reva ${ }^{1 \rrbracket}$ (iD) \\ ${ }^{1}$ LL.M. / PhD(c), Istanbul Medeniyet University, Medical Law Department, Turkey
}

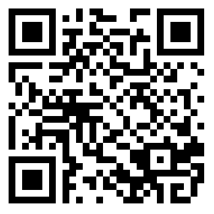

Received 5 December 2021

Accepted 16 December 2021

Published 31 January 2022

\section{CorrespondingAuthor \\ Zeynep Reva, \\ z_reva@yahoo.com \\ DOI \\ 10.29121/granthaalayah.v10.i1.2022 .4458}

Funding: This research received no specific grant from any funding agency in the public, commercial, or not-for-profit sectors.

Copyright: (C) 2022 The Author(s). This is an open access article distributed under the terms of the Creative Commons Attribution License, which permits unrestricted use, distribution, and reproduction in any medium, provided the original author and source are credited.

\section{ABSTRACT}

Context and Aim: The World Health Organization defines traditional and complementary medicine (TCM) practices as "the sum total of the knowledge, skills, and practices based on the theories, beliefs, and experiences indigenous to different cultures, whether explicable or not, used in the maintenance of health as well as in the prevention, diagnosis, improvement or treatment of physical and mental illness". This study aims to analyse the main legal regulations on TCM practices in Turkey.

Methodology: The study is based on a systematic review and analysis of desk research and data in the literature. TCM practices were analysed by reviewing the literature screening in particular data of the Ministry of Health, the CAMbrella study which had been conducted by the European Union and the WHO Global Report on Traditional and Complementary Medicine 2019. The literature review was carried out in "Ulakbim Turkish Academic Network and Information Center", "Google Scholar ". The research was made between September 2021 and October 2021, and 5 keywords were used: "traditional medicine", "complementary medicine", "integrative medicine", "alternative medicine" and "functional medicine".

Findings: TCM practices in Turkey are based on the Supplementary Article 13 of the Law No. 1219 on the Practice of Medicine and Medical Arts, Article 9/c and Annex 11 of the Health Services Basic Law No. 3359, and the Presidential Decree No. 1. Traditional and Complementary Medicine Practices Regulation ("Regulation"), dated 2014, stipulates the TCM practices in 15 areas, including acupuncture, apitherapy, phytotherapy, hypnosis, leech, homeopathy, chiropractic, cupping, larva, mesotherapy, prolotherapy, osteopathy, ozone, reflexology, and music therapy. Although the regulation basically specified the qualifications of TCM practitioners, the minimum requirements of the practice centres, and in which cases TCM practice can be imply or not, the issues such as the obligation to informed consent regarding TCM practices, medical malpractice regarding TCM practices is not fully regulated. In this respect, it is required to make comprehensive and detailed regulations on these issues.

Conclusion: TCM practices fill an important gap in terms of human health in areas that modern medicine cannot deal with. It is important to make the necessary legal regulations, especially to regulate informed consent; to define the care standards for medical malpractices regarding TCM practices, to strengthen the evidence base of TCM practices just like the conventional medicine practices.

Keywords: Traditional Medicine, Complementary Medicine, Integrative Medicine, Alternative Medicine, Functionel Medicine.

\section{INTRODUCTION}

Since the existence of mankind on earth, there has been a search for healing and an understanding e of medicine that has been with the possibilities, accumulations and experiences of each era. Complementary and alternative 
medicine is getting increasingly popular worldwide and national surveys show that great percentages of the population us eat least one type of complementary and alternative medicine every year Eisenberg et al. (1993). In the traditions of almost every society there are practices related to the fight against diseases. Some of them are evidence-based in today's scientific paradigm, while a significant portion exist based on experiments and observations conducted over the years (2). Traditional and complementary medicine (TCM) practices also exist as an important complement to evidence-based modern medicine, which has existed based on trial and observation over the years and is also called conventional medicine. This study aims to analyze TCM practices in Turkey with a legal dimension.

\section{MATERIAL AND METHOD}

The study is based on a systematic review and analysis of research and data in literature. TCM practices were analyzed by reviewing literature, in particular information in the World Health Organization's 2019 Traditional and Complementary Medicine Global Report, and the CAMbrella study carried out by the Health Ministry within the European Union. Literature review was carried out on "Ulakbim Turkish Academic Network and Information Center", "Google Scholar", by using the four keywords of "traditional medicine", "complementary medicine", "integrative medicine", "alternative medicine" and "functional medicine" between July 2021 and August 2021.

\section{FINDINGS}

\subsection{DEFINITION AND CONCEPTUAL OVERVIEW}

The World Health Organization (WHO) defines "traditional medicine" as the totality of knowledge, skills and practices based on theories, beliefs and experiences specific to different cultures that are used to protect, diagnose, cure or treat physical and mental illnesses, as well as to maintain good health. (2)

WHO has recently defined TCM; by dividing it into subcategories as traditional medicine, complementary medicine, and herbal medicine? (3) (Figure 1)

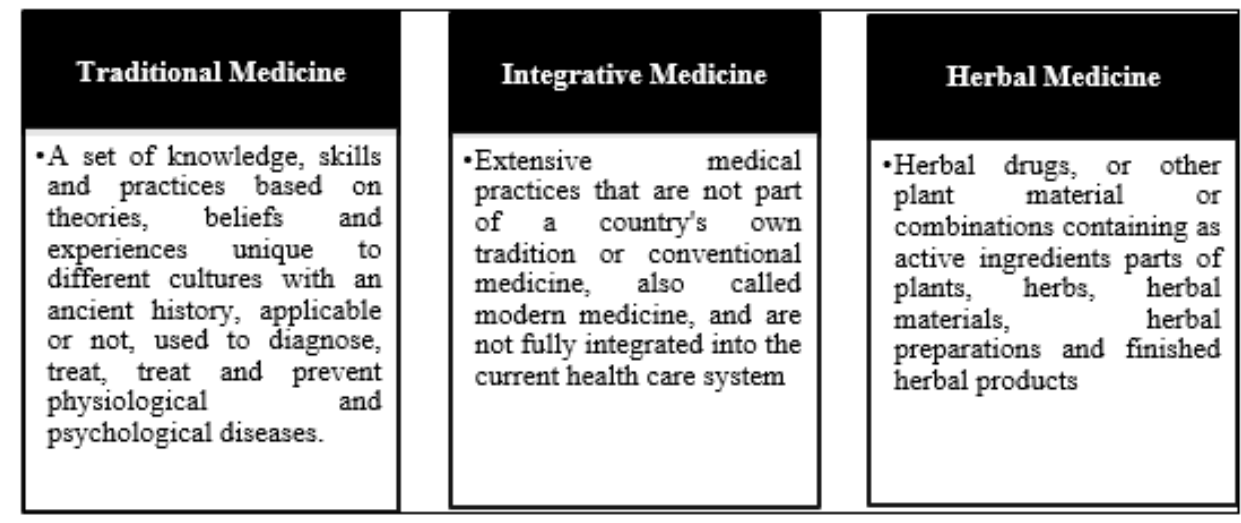

Figure 1 Definition of TCM by WHO

\section{WHO (2016)}

The European Parliament and the Parliamentary Delegation of the Council of Europe preferred to use the term "non-conventional medicine". (5) 
In European countries, it is evident that the term "Complementary and Alternative Medicine" (CAM) is preferred. Wiesener et al. (2012)

Eisenberg et al. (1993) stated that unconventional, alternative, or unusual treatments are difficult to define because they cover a wide range of practices and beliefs and defined non-conventional treatments as medical interventions such as acupuncture, chiropractic, and massage therapy that are not commonly taught in United States (USA) medical schools or are not generally practiced in US hospitals.

When we look at the terminology and diagnoses in our country, there are various uses and definitions. Kaplan (2010), considers the concepts of traditional and alternative medicine to be the same in content, but differentiates them according to the geographies in which they are seen. Kaplan states that traditional medicine is termed as local medicine, folk medicine and accepts the term traditional medicine for the geographies where medical practice was born and is associated with, which are not covered by modern medicine, while he accepts the term alternative medicine for other geographies. For example, while yoga, which is very popular in western culture, is considered as alternative medicine for western society, it is considered traditional medicine for the Indian society, where yoga was born and developed, and even uses the concepts of alternative medicine and complementary medicine as equivalents.

Oğuz (1996), on the other hand, stated that alternative medicine aims to be an alternative to conventional medicine, which is also called modern medicine, and traditional medicine, and argues that alternative medicine has been trying to systematize, institutionalize and organize in recent years, that the organization in traditional medicine remains at the traditional level, there is no systematization and institutionalization effort, and traditional medicine has a more local characteristic compared to alternative medicine. Oğuz (1992). Kaplan, on the other hand, states that the concepts of "complementary" or "alternative" are reproduced forms of traditional medicine. Kaplan (2010)

While Mollahaliloğlu et al Mollahaliloğlu et al. (2015), state that the concepts and definitions of complementary medicine and alternative medicine are not fully settled, that while some circles express the supportive use of modern medicine in the treatment of the patient as "complementary medicine", that it is emphasized that "alternative medicine" and non-standard medicine practices should be understood, and that some circles define all kinds of treatment attempts that are not scientifically proven - whether supportive or not - as "alternative medicine". Mollahaliloğlu et al. stated that the term "alternative medicine" has been used in our country for many years in a similar sense with other definitions, but in recent years, as a result of discussions on the subject both by WHO and international organizations and in our country, and that this concept has begun to be abandoned with the emphasis that treatment can have an alternative, but medicine cannot, and its widespread use today is mostly in the form of "traditional and complementary medicine".

When we look at the legal regulations of our country, the terminology of traditional and complementary medicine (TCM) practice is preferred, and the definition of TCM is not made in legal regulations such as laws, presidential decrees, decree laws and regulations, it is seen that TCM practices are limited to the areas determined in the TCM Regulation in Article 8/1 of the Traditional and Complementary Medicine Regulation ("TCM Regulation") issued in order to determine the traditional and complementary medicine practice methods for human health, to train and authorize the people who will apply these methods, and to regulate the working procedures and principles of the health institutions where these methods will be applied. 
When we look at the legislation, doctrines and practices, both foreign and domestically, it is evident that the terminology contains a tremendous variety. For conventional medicine, which has appeared as the modern face of today's medical science, it seems that terms such as western medicine, modern medicine, allopathy, classical medicine are used. In terms of TCM practices, it is seen that terms such as traditional medicine, complementary medicine, alternative medicine, folk medicine, folkloric medicine, functional medicine, naturopathic medicine, integrative medicine is sometimes used interchangeably, sometimes with differences in meaning.

Although it is also found that the term "holistic medicine" is used in practice, the terminology used in legal regulations for TCM practices is the terminology of "traditional and complementary medicine (11). In 2020, the name of the Department of Traditional and Complementary Medicine Practices was expanded to include functional medicine practices and became the Department of Traditional, Complementary and Functional Medicine Practices. This has led to the interpretation that the terminology "traditional, complementary and functional medicine" is now preferred in terms of terminology.

\section{TCM PRACTICES IN TURKEY 4.1. LEGAL REGULATIONS REGARDING TCM}

TCM practices in our country are regulated legally; its main legal basis is from the Additional Article 13 of the Law No. 1219 on the Practice of Medicine and is derived from the Health Services Basic Law No. 3359, article 9/c and Annex 11, and the 2014 Traditional and Complementary Medicine Practices Regulation (12) ("Regulation") issued based on the Presidential Decree no.1.

\subsection{REGULATOR OF TCM PRACTICES}

The official authority regarding TCM practices is the "Department of Traditional, Complementary and Functional Medicine Practices" within the General Directorate of Health Services under the Ministry of Health. The name of the department is" Department of Traditional and Complementary Medicine Practices ", while it was organized as" Department of Traditional, Complementary and Functional Medicine Practices" with a change made in 2020.

The duties of the Department of Traditional, Complementary and Functional Medicine Practice are as follows: (13)

- To determine the standards related to traditional and complementary medicine practices,

- To determine the qualifications of traditional and complementary medicine practitioners and to carry out studies on certification of their qualifications,

- Conducting operations related to the issuance and revocation of licenses to centers that will operate in the fields of traditional and complementary medicine practice, as well as their activities,

- Keeping records of institutions providing education about traditional and complementary medicine practices,

- Monitoring traditional and complementary medicine practice centers and practitioners, preventing activities and promotions that are contrary to regulations and permits, 
- To monitor developments and practices related to functional medicine practices and to make arrangements related to this field,

- To perform other duties assigned by the General Director.

\subsection{TCM PRACTICES ARRANGED IN LEGISLATION}

The regulation regulates the practice of TCM in a total of 15 areas: acupuncture, apitherapy, phytotherapy, hypnosis, leech, homeopathy, chiropractic, cupping (hacamat), larva, mesotrapy, prolotherapy, osteopathy, ozone, reflexology, and music therapy. The regulation basically specifies the qualifications of TCM practitioners, the minimum requirements of the practice centers, and in which situations TCM practice can be carried out or not.

The regulation defines 15 TCM practices as follows. (14)

Acupuncture: It is a practice that is made by stimulating the special points found in the body, with stimulation methods such as needles, laser beams, electrical stimulation, cups, seeds, needle or magnetic balls for the ear, thermal stimulation, acupressure and sound or electrical or magnetic vibrations implemented by a certified physician or by a dentist who has received practical training in the relevant field to practice in the field.

Apitherapy: It is the use of bee and bee products as complementary and supportive treatment of some diseases.

Phytotherapy: It is a medical treatment method made with traditional herbal medicinal products and herbal medicines.

Hypnosis: It is a process designed to achieve or result in changes in the consciousness and awareness, body, feelings, emotions, thoughts, memory or behavior of another person through indoctrination.

Leech: It is a practice made using a "medical leech" called "Hirudo medicinalis and Hirudo verbana".

Homeopathy: It is a holistic practice method aimed at improving the health status with selected homeopathic medicines specific to the person.

Chiropractic: It is a supportive field of practice that deals with the prevention of biomechanical disorders of the muscles, spine and skeletal system and the problems it causes on the nervous system.

Cupping (hacamat): It is a dry cup practice based on creating a localized vacuum to increase blood circulation and a wet cup practice where blood is taken by creating superficial skin cuts with a localized vacuum at certain body points.

Larva (Maggot Therapy): The practice of Lucilia (Phaenicia) sericata sterile larvae for biodebriding purposes in chronic wounds.

Mesotherapy: It is the practice of regional, small doses, intradermal injection of herbal or pharmacological drugs aimed at the healing of organ pathologies caused by the mesoderm, with special needles and special techniques.

Prolotherapy: It is the practice of injecting proliferative and irritant solutions into the joint connective tissue (usually damaged, worn tendons and ligaments with reduced strength, as well as joints).

Osteopathy: It is a non-invasive complementary medicine practice that helps to strengthen the musculoskeletal system including joints, muscles, connective tissue and the spine, focuses on total body health and focuses on the effectiveness of the musculoskeletal system in diseases. 
Ozone Therapy: It is a method of practice in which ozone-oxygen mixtures are used locally or systemically. A certain amount of the patient's blood is mixed in sterile conditions outside the body, under normobaric conditions with an appropriate amount of medical ozone and returned to the patient.

Reflexology: It is based on the principle of the presence of guiding reflex areas related to all parts of the body, organs and glands on the hands, soles of the feet and ears, and only pressure is applied to the reflex areas without using any devices, materials, creams, lotions.

Music therapy: It is an practice in which music and music practices are used clinically and evidence-based to meet the physical, psychological, social and mental needs of individuals by a professional qualified in music therapy.

\subsection{NUMBER OF TCM USERS}

TCM practices are used by many people in our country, but there are no official statistics on their percentage of use.

Although there is no comprehensive study in our country, there are crosssectional studies on the use of TCM practices in different diseases. A study conducted on patients with breast cancer revealed that $87 \%$ of patients used TCM practices Yavuz et al. (2007). There are studies that show that 57.4\% Durusoy et al. (2010) of patients with acne vulgaris and 22.2\% Bahceci et al. (2013) of patients with psychiatric disorders use TCM practices.

\subsection{REQUIRED DOCUMENTS IN TCM UNIT AND TCM PRACTICE CENTER PERMIT PRACTICE FILE (REGULATION, ANNEX-}

\section{3)}

- A signed practice petition requesting the initiation of operations related to the opening of a unit/practice center with the name or trade name of the health care provider's operator.

- A list showing which practices will be carried out and the tools and equipment to be used,

- A Directorate-approved sample of the Ministry's registered practice certificate for the relevant field of practice for medical and dental doctors.

- Certificate of education or trainings received by health professionals working in the unit/practice center.

- A list showing all the staff who will work in the unit/practice center, T.R. identification number statement and two photographs.

- In private hospitals, the project based on the license obtained for the center by the Ministries, a project with a scale of at least $1 / 100$ in public and university hospitals, where the sections and facades of the whole building are shown, floor plans prepared in three sets of blueprints to be certified by the author and the provincial directorate of environment and urban planning.

- Department project review report.

- Joint technical report to be prepared as a result of on-site inspection by the Directorate. 


\subsection{PERSONNEL AUTHORIZED TO IMPLEMENT TCM}

In the Regulation on who can apply TCM practices, each practice type is specified individually: Yavuz et al. (2007)

Acupuncture: A certified doctor who has received practical training in the relevant field or a dentist to practice in their own field.

Apitherapy: Certified physician.

Phytotherapy: Certified physician and dentist.

Hypnosis: Certified physicians and dentists, clinical psychologists under the supervision of a physician, and psychologists with a license for medical practices of psychology.

Leech: Certified physician and healthcare professional under the supervision of a physician.

Homeopathy: Certified physician and dentist.

Chiropractic: Certified physician and certified healthcare professional under the supervision of a physician.

Cupping (hacamat): Certified physician, dentist, and certified healthcare professional under the supervision of a physician.

Larva (Maggot Therapy): Certified physician.

Mesotherapy: Certified physician and dentist.

Prolotherapy: Certified physician and dentist.

Osteopathy: Certified physician and dentist.

Ozone Therapy: Certified physician and dentist.

Reflexology: Certified physician and certified healthcare professional under the supervision of a physician.

Music therapy: An individual who has completed a music therapy certification program after receiving music education at least at the undergraduate level with members of the medical profession under the supervision of a certified physician and a physician who helps the practice.

Training programs for TCM practices can only be organized by university hospitals and training and research hospitals affiliated with the Ministry of Health and with the authorization of the Ministry of Health. TCM training is provided by physicians and health professionals with traditional medicine training. The training is designed as a combination of distance education, formal education, and clinical practice. Certificates approved by the Ministry of Health are provided to physicians, dentists and other participants who receive regular training and who have achieved success in the exam held at the end of the training.

\subsection{INSURANCE ASPECT}

TCM practices are not covered by general health insurance in accordance with Article 64 of Law No. 5510. However, some practices that are similar to traditional medicine, such as physical medicine, rehabilitation practices, and spa practices, are partially or completely covered by insurance, provided that they have been prescribed by a qualified physician. While private health insurance companies also do not yet reimburse TCM practices within the scope of insurance coverage, but they are working on this issue. 


\subsection{MEDICAL MALPRACTICE ASPECT}

There are no regulations regarding the fact that a TCM practitioner makes a medical practice error in terms of TCM practices. In this respect, it will be necessary to evaluate whether the physician /dentist who performs the TCM practice meets the requirements of medical science based on the criterion. However, in this case, it is important that the standard operational procedure Polat (2019) for the practice of TCM, that is, the standard of care established based on objective, scientific and reference, is established and standardized. The physician: while performing medical intervention, must follow and apply the medical standard. As a matter of fact, in accordance with the settled Supreme Court case law; while conducting medical studies, the physician is responsible for fulfilling some professional conditions, valuing the condition of the patient, and observing and applying the rules of medical science in a broad sense. Hakeri (2015)

The implementation of TCM practices by unauthorized persons is a medical intervention performed by unauthorized persons and constitutes a crime. According to the Law No. 1219 on the Practice of Medicine and Medical Sciences, Article 25 "The individual who treats a patient or assumes the title of physician, despite not holding a diploma, even if it is not for the purpose of gaining benefit, is punished with imprisonment from two years to five years and a judicial fine up to a thousand days." imprisonment and judicial fine will be applied.

\section{CONCLUSION}

TCM practices are a health service that has an important place in the prevention and management of lifestyle-related chronic diseases, especially in meeting the health needs of an aging population but is often underestimated. WHO (2019)

There are many practices both in eastern societies and in western societies as a complement to modern medicine. TCM practices fill an important gap in terms of human health in areas that modern medicine cannot deal with.

The interest in TCM practices is increasing each day. While only 98 WHO Member States had developed national policies on TCM until 2018, in 2019 this number had increased to 109. In addition, 124 member states have also implemented regulations on herbal medicine. In An ideal world, TCM practices are an option offered by a well-functioning, human-centered healthcare system that balances preventive care and therapeutic services. Reva (2019)

It is important to make the necessary legal arrangements for the regulation of TCM practices on a scientific scale, just like in modern medical practices, in particular to establish standards of care for informed consent and malpractice, to regulate civil and criminal liability for malpractice Reva (2019). TCM, unlike conventional medicine, is based on experience and beliefs, rather than scientific criteria and grounds. This, in turn, makes the wider scale clarification necessary Sögüt (2017). In our country, there is no informed consent regulation or guide for TCM practices, and informed consent regulations that apply in principle to health care professionals will also apply to TCM practices. In this context, the physician and dentist who will perform the TCM practice, prior to the TCM practice, is responsible for informing the patient about the issues of; "The probable causes of the disease and how it will progress, by whom, where, how and with what method the medical intervention will be performed and its estimated duration, other diagnosis and treatment options, the benefits and risks of these options, the possible effects on the patient's health, possible complications, possible consequences in case of rejection, benefits and risks, important features of the drugs to be used, lifestyle suggestions 
that are critical for health, how to reach medical help on the same issue when necessary."(24 ). Article 10/5 of the Regulation on Traditional and Complementary Medicine Practices also stipulates that an "Information and Consent Form" should be prepared in accordance with the Patient Rights Regulation and that consent should be obtained from all patients. It is important that the indication is clearly regulated in TCM practices in terms of both the safety of the patient and the prevention of fraud and abuse of these relevant methods. The regulation limited the areas where TCM practices could be applied and introduced special regulations regarding the indication. The scientific commission established in accordance with the regulation is responsible for determining the areas of practice and providing an opinion on the indications and side effects of practices that may occur.

It is important and necessary to develop norms, standards and technical documents based on reliable information and data on the safe, qualified, and effective regulation of TCM practices and their proper integration into health systems.

\section{REFERENCES}

Bahceci B, Bağcıoğlu E, Öztürk A, Bülbül F, Şahiner IV, Eryonucu Tuncer B, Güzel Hİ, Hocaoğlu Ç. (2013) Complementary and alternative medicine use in patients with mental disorders in Turkey. Complement Ther Clin Pract. 2013 Nov ;19(4) :221-6. doi : 10.1016/j.ctcp.2013.06.005. Epub Jul 24. PMID : 24199977. Retrieved from https://doi.org/10.1016/j.ctcp.2013.06.005

Council of Europe (1999), Social, Health and Family Relations Committee Report, European Approach to Unconventional Medicine Practice, 11 June, http://assembly.coe.int/nw/xml/XRef/X2H-Xref-ViewHTML.asp?FileID $=8014$ Access Date : 11.12 .2021

Directive on Duties of Departments of the General Directorate of Health Services, which entered into force with the approval of the Ministry, dated 15/06/2020 and numbered 54567092-010.04-E.2812.

Durusoy Ç, Gülec AT, Durukan E, Bakar C. (2010) Use of Complementary and Alternative Medicine in Acne Vulgaris and Melasma Patients Applying to the Dermatology Clinic : A Questionnaire Study. Turkish Thoracic Journal ; Ankara Vol. 11, Iss. 1, Mar : 14-17.

Eisenberg DM, Kessler RC, Foster C, Norlock FS, Calkins DR and Delbanco TL. (1993) Unconventional Medicine in the United States, Prevalence, Costs, and Patterns of Use. January 28, 1993 N Engl J Med ; 328 :246-252 DOI : 10.1056/NEJM199301283280406 Retrieved from https://doi.org/10.1056/NEJM199301283280406

Hakeri H. (2015) Legal Situation in Our Country in terms of Traditional Medicine. Journal of Medical Law, Year Issue 7.

Kaplan M. (2010) Women in the Reproduction Process of Traditional Medicine and Intergenerational Conflict in the Case of Ankara City, Ankara University Rectorate Publications : 257, Ankara, p. 118

Mollahaliloğlu S, Uğurlu FG, Kalaycı M, Öztaş D. (2015) New Era in Traditional and Complementary Medicine Practices. Ankara Medical Journal 15 / 2, January. Retrieved from https://doi.org/10.17098/amj.44789

Oğuz NY. (1996) Alternative Medicine and Folk Medicine in Terms of Society, Science and Medical Ethics, Journal of Science and Utopia, p. 25, p. 36. 
Oğuz, NY. (1992) The Methodological and Ethical Risks of Alternative Medicine Against Psychiatry", Turkish Journal of Psychiatry, , Vol. 3, P. 1, p. 37.

Polat O, (2019) Medical Malpractice, Seçkin Publishings, Ankara, 3. Edition.

Regulation on Patient Rights, Article 15. For the text of the regulation, see : Turkish Official Gazette dated 01.08.1998 and numbered 23420

Regulation on Traditional and Complementary Medicine Practices, Annex 13 : Required Documents in TCM Unit and TCM Practice Center Permit Practice File

Regulation on Traditional and Complementary Medicine Practices, Annex-3 : List of Practices That Can Be Done in Units and Practice Centers.

Republic of Turkey Ministry of Health, 2nd International Traditional and Complementary Medicine Congress, 24-27 April 2019, Congress Summary Book, Istanbul p.12

Reva Z, (2019) Legal Dimension of The Traditional And Complementary Medicine Practices In Turkey, 7th European Association of Health Law Congress, Innovation \& Healthcare New Challenges for Europe, 25-27 September, Toulouse (3rd Best Poster Award)

Sögüt, İS. (2017) Informed Consent Problem in Traditional and Complementary Medicine Practices. prof. Dr. iur. Gift to Merih Kemal OMAĞ - Volume : II. Journal of Istanbul Kultur University Faculty of Law Issue : 2 - July.

The name of the regulation, which is the most basic text regulating TCM practices, is the "Regulation on Traditional and Complementary Medicine Practices".

Turkish Official Gazette dated 27.10.2014 and numbered 29158.

WHO (2019), Global Report On Traditional And Complementary Medicine,

WHO (2016), General Assembly Decision No. WHA69. 24, Retrieved from https://apps.who.int/gb/ebwha/pdf_files/WHA69/ A69_R24-en.pdf Access Date : 10.10.2021

WHO (2021) https://www.who.int/traditional-complementary-integrativemedicine/about/en/ Access Date : 30.11.2020

Wiesener S, Falkenberg T, Hegyi G, Hök J, Roberti di Sarsina P, Fønnebø V. (2012) Pan-European research network for Complementary and Alternative Medicine (CAM) Final report of CAMbrella Work Package 2 (leader : Vinjar Fønnebø) Legal status and regulation of CAM in Europe Part I - CAM regulations in the European countries,

Yavuz M, Özcan İA, Kaymakcı S, Bildik G, Dıramalı A. (2007) Investigation of the Use of Complementary and Alternative Treatment Methods in Patients with Breast Cancer, Turkiye Klinikleri J Med Sci ; 680-686. 